\title{
Supporting medication adherence for adults with cystic fibrosis: a randomised feasibility study
}

Daniel Hind ${ }^{1 *}$ (D, Sarah J. Drabble², Madelynne A. Arden³, Laura Mandefield ${ }^{1}$, Simon Waterhouse ${ }^{1}$, Chin Maguire ${ }^{1}$, Hannah Cantrill', Louisa Robinson ${ }^{1}$, Daniel Beever ${ }^{1}$, Alexander J. Scott', Sam Keating ${ }^{1}$, Marlene Hutchings ${ }^{4}$, Judy Bradley ${ }^{5}$, Julia Nightingale 6 , Mark I. Allenby 6 , Jane Dewar ${ }^{7}$, Pauline Whelan ${ }^{8}$, John Ainsworth ${ }^{8}$,

Stephen J. Walters ${ }^{2}$, Alicia O'Cathain ${ }^{2}$ and Martin J. Wildman ${ }^{4}$

\begin{abstract}
Background: Preventative medication reduces hospitalisations in people with cystic fibrosis (PWCF) but adherence is poor. We assessed the feasibility of a randomised controlled trial of a complex intervention, which combines display of real time adherence data and behaviour change techniques.

Methods: Design: Pilot, open-label, parallel-group RCT with concurrent semi-structured interviews. Participants: PWCF at two Cystic Fibrosis (CF) units. Eligible: aged 16 or older; on the CF registry. Ineligible: post-lung transplant or on the active list; unable to consent; using dry powder inhalers. Interventions: Central randomisation on a 1:1 allocation to: (1) intervention, linking nebuliser use with data recording and transfer capability to a software platform, and behavioural strategies to support self-management delivered by trained interventionists $(n=32)$; or, (2) control, typically face-to-face meetings every 3 months with CF team $(n=32)$. Outcomes: RCT feasibility defined as: recruitment of $\geq 48$ participants (75\% of target) in four months (pilot primary outcome); valid exacerbation data available for $\geq 85 \%$ of those randomised (future RCT primary outcome); change in \% medication adherence; $\mathrm{FEV}_{1}$ percent predicted (key secondaries in future $R C T)$; and perceptions of trial procedures, in semi-structured interviews with intervention $(n=14)$ and control $(n=5)$ participants, interventionists $(n=3)$ and CF team members $(n=5)$.

Results: The pilot trial recruited to target, randomising 33 to intervention and 31 to control in the four-month period, June-September 2016. At study completion (30th April 2017), 60 (94\%; Intervention =32, Control =28) participants contributed good quality exacerbation data (intervention: 35 exacerbations; control: 25 exacerbation). The mean change in adherence and baseline-adjusted $\mathrm{FEV}_{1}$ percent predicted were higher in the intervention arm by $10 \%(95 \% \mathrm{Cl}:-5.2$ to $25.2)$ and $5 \%(95 \% \mathrm{Cl}-2$ to $12 \%)$ respectively. Five serious adverse events occurred, none related to the intervention. The mean change in adherence was $10 \%$ ( $95 \%$ Cl: -5.2 to 25.2), greater in the intervention arm. Interventionists delivered insufficient numbers of review sessions due to concentration on participant recruitment. This left interventionists insufficient time for key intervention procedures. A total of 10 key changes that were made to RCT procedures are summarised.
\end{abstract}

Conclusions: With improved research processes and lower monthly participant recruitment targets, a full-scale trial is feasible.

Trial registration: ISRCTN13076797. Prospectively registered on 07/06/2016.

\footnotetext{
* Correspondence: d.hind@sheffield.ac.uk

${ }^{1}$ Clinical Trials Research Unit, University of Sheffield, Regent Court, 30 Regent

Street, Sheffield S1 4DA, UK

Full list of author information is available at the end of the article
}

(c) The Author(s). 2019 Open Access This article is distributed under the terms of the Creative Commons Attribution 4.0 International License (http://creativecommons.org/licenses/by/4.0/), which permits unrestricted use, distribution, and reproduction in any medium, provided you give appropriate credit to the original author(s) and the source, provide a link to the Creative Commons license, and indicate if changes were made. The Creative Commons Public Domain Dedication waiver (http://creativecommons.org/publicdomain/zero/1.0/) applies to the data made available in this article, unless otherwise stated. 


\section{Background}

Cystic Fibrosis (CF) is an inherited long-term condition affecting over 80,000 people worldwide [1-5], mostly in people of Northern European ancestry [6]. People with cystic fibrosis (PWCF) typically die from lung damage at a median age of 31 years [1]. Preventative medications reduce exacerbations and preserve lung function [7-13]. There is a disparity between self-reported and objectively measured adherence to inhaled therapy, with recorded rates of 80 and $36 \%$ respectively [14]. It follows that, currently, clinicians are not able to identify people with low adherence and offer appropriate support. Low adherence predicts exacerbations requiring intravenous antibiotics (IVAB) $[15,16]$, which carry a risk of systemic side effects and increased mortality $[17,18]$, and result in higher care costs [19-21]. During 2012 the total UK spend for CF was estimated to be $£ 110$ million [22] of which $£ 30$ million was spent on inhaled antibiotics and mucolytics [23]; the following year the UK adults with CF population received 103,453 days of IVAB [24] with $54 \%$ occurring in hospital, [25].

Consistent with identified research priorities [26, 27], we developed a complex intervention to support adherence to preventive inhaled therapy. This paper summarises the intervention development process, presenting the results of the pilot randomised controlled trial (RCT) component of the feasibility study, and describing the resulting changes made to the intervention and research procedures, in advance of a full-scale RCT [28, 29].

The specific objectives of the feasibility study were:

1. To determine feasibility of a RCT based on:

(a) participant recruitment;

(b) participant retention;

(c) quality of primary outcome and other data at 5(+/1) month; and

(d) the acceptability and robustness of trial procedures

2. To carry out a process evaluation, consisting of quantitative and qualitative data on procedures and outcomes, in order to understand and mitigate potential sources of intervention failure in terms of contextual effects, inputs, engagement, activities and outcomes. The specifics of the process evaluation are detailed in a separate article, dedicated to this aspect of the study.

3. To document changes to research and intervention procedures for a future RCT, based on the findings. Changes to research procedures only will be documented in this report.

\section{Methods}

\section{Design}

The feasibility study in preparation for the full RCT consisted of a concurrent pilot RCT and a mixed methods process evaluation. The objectives of the pilot RCT were to determine feasibility of a full-scale RCT based on participant recruitment/retention, the quality of primary outcome data and the acceptability and robustness of trial procedures. This was a parallel group, open label, individually-randomised external pilot RCT with a 1:1 allocation ratio with additional semi-structured interviews. The protocol is available (Additional file 1); this report is compliant with Consolidated Standards of Reporting Trials (CONSORT) extension for randomised pilot studies [30] (Additional file 2).

\section{Participants}

We planned to recruit 64 participants between 1st June 2016 and 30th September 2016 from two CF Centres (Nottingham University Hospitals and University Hospital Southampton). The CF registry provided a list of potentially eligible patients for each site. Medical notes were then reviewed to select those aged 16 years and over, taking - or willing to take - inhaled mucolytics or antibiotics via a nebuliser with data recording and transfer capability. We excluded those who were: post-lung transplant, on the active transplant list, receiving palliative care, lacking capacity for informed consent, or using dry powder devices to take antibiotics or mucolytics.

A purposive sample of intervention arm $(n=14)$ and control arm participants $(n=5)$, as well as interventionists ( $n=30.8$ WTE at each centre) and members of the wider, multi-disciplinary CF team $(n=5)$ was used to conduct semi-structured interviews, assessing acceptability and robustness of RCT procedures. Participants were selected based on site, age, gender and deprivation index. Postcodes were used to generate an Index of Multiple Deprivation (IMD) quintile. Service-users were selected based on objective and subjective adherence levels (respectively indicated by nebuliser-recorded inhalation data and a self-report question administered at baseline, asking "Thinking back to the last two weeks. What percentage of your nebuliser treatments have you taken?"). Professionals were selected based on site and professional category.

\section{Consent and randomisation}

Eligible participants were invited to give written informed consent to engage in the pilot RCT. For most participants we obtained consent to have their adherence data collected beyond their active trial period, until 30 April 2017. Participants were randomised to intervention or control arms using a computer-generated pseudo-random list and random permuted blocks of varying sizes (2,4 and 6), 
stratified by site and number of IVAB days in the previous 12 months ( $\leq />14$ days) [24].

PWCF that consented to be approached for interview were contacted by letter or mail and subsequently telephone or email, dependent on preference. Professionals were contacted directly by the study team. Patients were interviewed once and interventionists were interviewed at both the beginning and the end of the study. Semi-structured interviews were conducted face-to-face, digitally audio-recorded and verbatim transcribed.

\section{The complex intervention}

The intervention has four elements, two of which are also used for data collection purposes in the control arm of the trial

1. eTrack (PARI Pharma GmbH, Starnberg, Germany) nebulisers to deliver inhaled medications and provide monitoring functions. eTrack nebulisers send timestamped inhalation data to a 2net Hub (Qualcomm, San Diego, USA), which enables realtime monitoring. The devices could not distinguish between different drugs administered through the nebuliser; whilst it is theoretically possible for patients to press different buttons depending on the drug, our experience is that any additional step in nebuliser therapy decreases the probability that it will be completed. In addition, relying on participants pressing buttons to distinguish between drugs may have introduced an additional source of error if buttons were incorrectly used;

2. CFHealthHub server infrastructure receives the inhalation data in real-time from PARI, stores the data securely and presents this for display on the CFHealthHub apps (see Fig. 2);

3. CFHealthHub apps - with behaviour change tools and educational content to render the received data and present it to clinicians via the website, and to patients via website and mobile apps; and,

4. A manualised behaviour change intervention used by trained health professionals in their interactions with PWCF.

Both intervention and control groups received a nebuliser with data recording and transfer capability, which measured their adherence to medication. The adherence data for the control group was not visible to participants, interventionists or the care team throughout the trial. In the intervention group, the adherence data was visible to the interventionist only for a two- to fourweek baseline period, following this it was also made visible to both the participants and care team. The control group continued with usual care.
The intervention group had access to: (1) information technology infrastructure which captures, stores and displays adherence data; (2) online adherence feedback and tailored modules of behaviour change content; (3) an initial visit, and at least one additional review visit, from a trained interventionist who delivered face-to-face behaviour change content. The behaviour change content was linked to online content and therapists provided support and guidance in line with, and interacting with this. Interventionists were trained through a two-day, face-to-face workshop, online learning modules and a structured four-week training programme, with an online theory test and competency assessment of the intervention delivery within the first 5 sessions.

\section{Summary of the intervention development process}

The intervention was developed as follow: The Sheffield Microsystems Coaching Academy [31] worked with the Sheffield adult CF team to carry out a "Five Ps" strategic analysis [32]. The CF team identified their overarching purpose to be to enable PWCF to live as normal a life as possible and their objective to shift from disruptive hospital-based rescue to community-based prevention [33]. Understanding the link between medication adherence and preserved lung function [7-13], our aim became that PWCF should lose less than $2 \%$ of lung function each year. We reviewed the evidence for barriers to adherence to $\mathrm{CF}$ medication and the effectiveness of interventions for improving adherence [34, 35]. We used a quality improvement technique, process mapping [36], which highlighted the need for objective medication adherence data in the CF unit. Software engineers developed data capture, download and feedback systems for nebulisers. We used statistical process control to analyse data logged by nebulisers, thereby better understanding common and special cause variation in adherence $[37,38]$. We modelled the use of adherence indices which take into account the percentage of the regimen taken and its appropriateness [39]. We explored barriers and beliefs about adherence $[40,41]$, using objective adherence data as a prompt in interviews [42] and the Theoretical Domains Framework (TDF) [43-45] to analyse the barriers and facilitators. We used the 'COM-B' system [46], the behaviour change wheel $[47,48]$ and TDF [43] to identify suitable intervention functions and behaviour change techniques with reference to two theories of behaviour: Social Cognitive Theory [49], which emphasises the importance of self-efficacy, outcome expectancies, environmental factors, and goal setting on behaviour; and, Control Theory [50], which suggests that self-/monitoring and feedback are effective in closing the gap between reality and goals, thereby promoting habit formation. We used a Markov model to estimate the incremental cost-effectiveness of adding an 
adherence intervention to control [51]. We produced a logic model (Fig. 1) expressing the processes by which we expected our intervention to work in terms of inputs, engagement, activities and outcomes.

We produced the software platform, CFHealthHub (Fig. 2), with feedback from PWCF, clinicians, the software team and user experience (UX) design company, using Agile methods [52, 53]. The platform is compliant with regulatory, data protection, security and interoperability standards [54-57]. Following best practice guidelines [58], we used prototypes and wireframes to design the website and mobile apps [59], combining evidence-based [60] and user-centred design principles to define requirements, refine the user interface and enhance usability [61]. Short-cycle software releases allowed rapid user feedback and beta-testing of the digital platform by researchers, clinicians and patients (Additional file 3) [62-66]. Theory-based user-engagement strategies, tracking and click analytics and summaries of user 'point-and-click' web data, generated to describe the individual's online activity, were built into the website and mobile apps. We incorporated short films, some which explained how medications work, others in which PWCF share experiences of forming treatment adherence habits ('talking heads'). The digital platform has been running continuously since August 2015, receiving and presenting inhalation data in real-time from Pari eTrack nebulisers. Three physiotherapists gave verbal feedback at two time-points during the development of a training course, manual and reporting tools developed to guide and document interactions with patients using $\mathrm{CFHH}$. Fidelity assessment sheets were developed for these interactions based on the $\mathrm{Na}$ tional Institute for Health process [67, 68].

\section{Sample size}

In the proposed full-scale trial, we hoped that $15 \mathrm{CF}$ units would each recruit 46 patients in six months (8 patients per centre per month). To match this rate, our two-centre pilot needed to recruit 64 participants in its four-month accrual window. To progress to a full-trial our recruitment target was to consent and randomise 48 participants at two centres over four months, which was $75 \%$ of the rate required in the main trial. A second progression criterion was attrition from contribution of exacerbation data of no more than $15 \%$ of randomised participants at $5( \pm 1)$ months. This sample would also give us sufficient confidence to predict recruitment and retention in the full-scale RCT with sufficient precision [69-72].

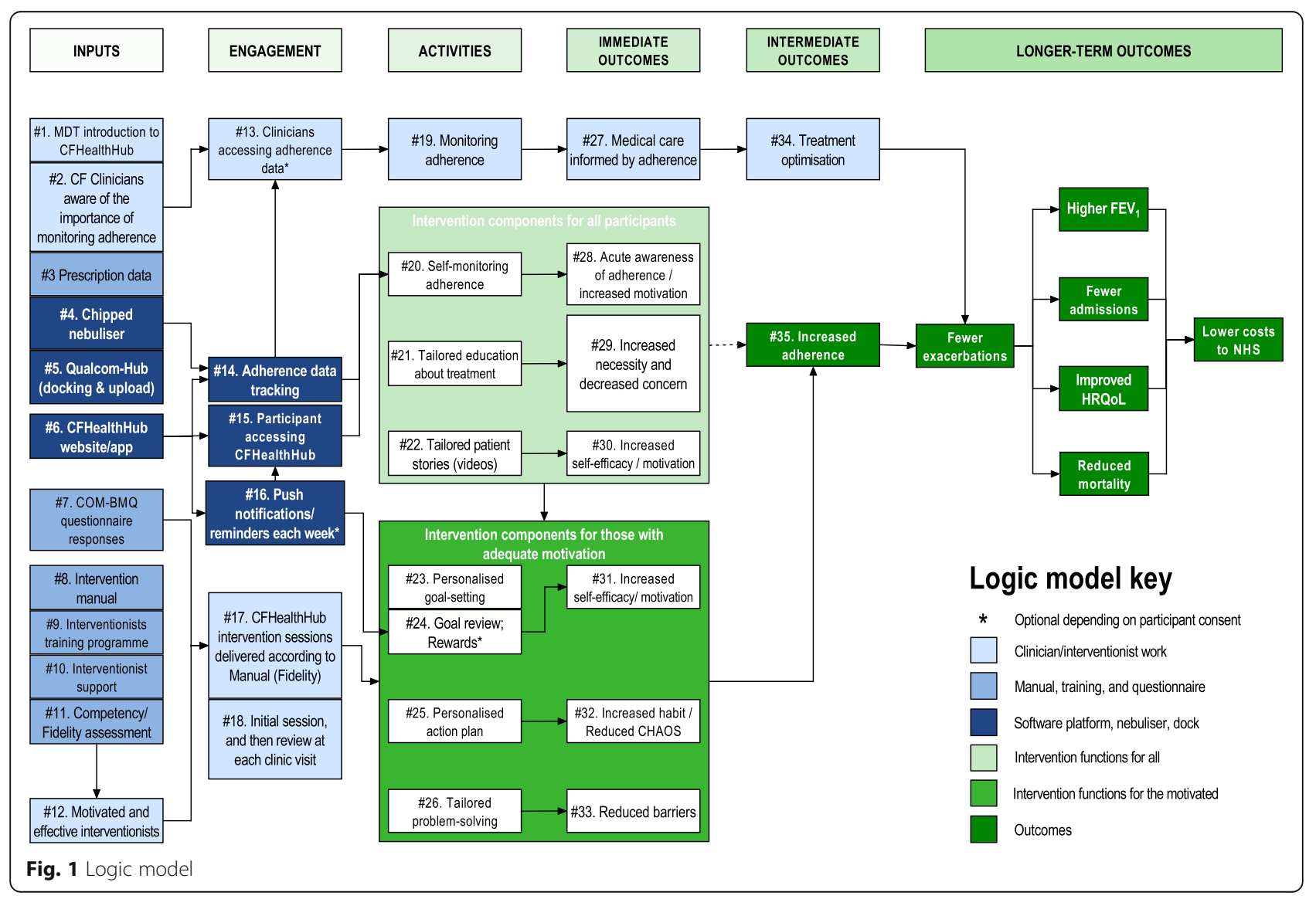




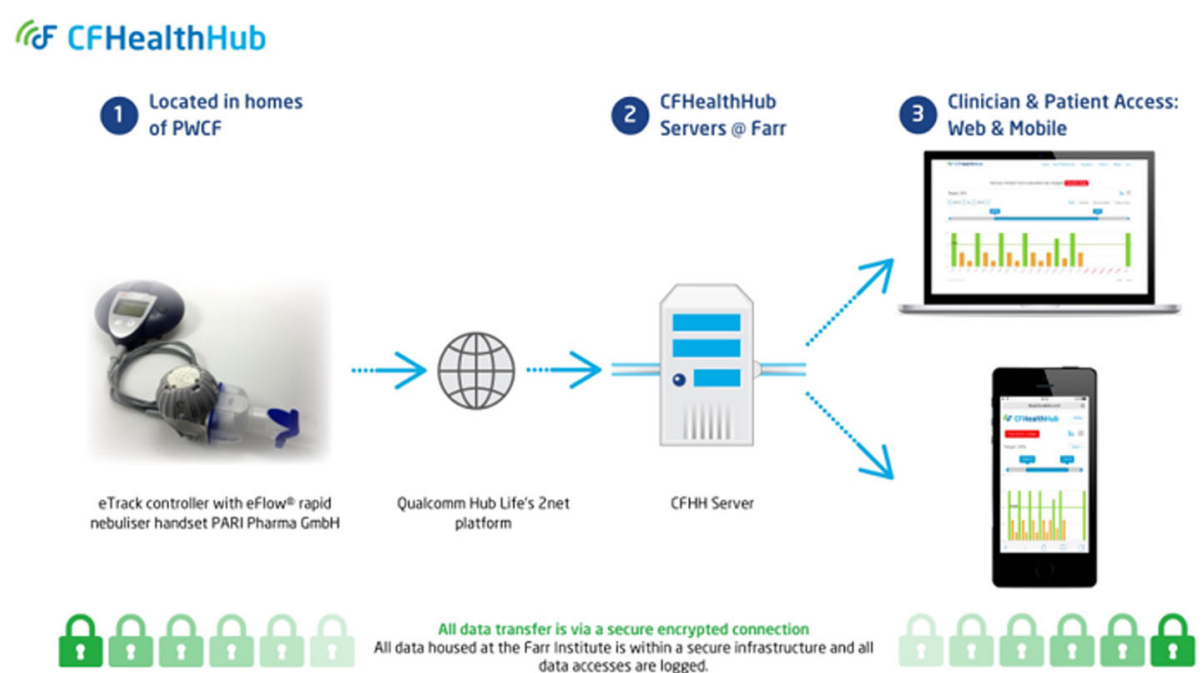

Fig. 2 The digital platform

\section{Outcomes}

Outcomes of interest mapped directly onto the objectives:

(a) participant recruitment of $\geq 48$ participants (75\% of target) in four months;

(b) participant retention, defined as $\geq 85 \%$ of those randomised contributing exacerbation data at study completion;

(c) quality of primary outcome and other data at $5(+/-1)$ month. We assessed the ability of study staff to collect valid data for the full-scale trial's proposed primary outcome, the number of pulmonary exacerbations. Defined according to the modified Fuchs' criteria [73], a pulmonary exacerbation was said to have occurred if a patient was treated with intravenous antibiotics for any one of 12 signs or symptoms (Additional file 1). An exacerbation form was administered by the site interventionist at each clinical encounter, with every study participant. The form captured whether there was a clinical need for a course of IVABs, which Fuchs' criteria were met and whether participants accepted treatment IVABs. Secondary clinical outcomes are listed in Table 1 and were collected as baseline and $5(+/-1)$ month post-randomisation.

(d) the acceptability and robustness of trial procedures, assessed through semi-structured interviews, reports recorded on our log of problems, management group and patient and public involvement (PPI) meetings.

There are three reasons for defining the primary outcome in terms of the modified Fuchs' criteria [73]. First, to avoid excessive ascertainment bias in intervention group participants who would be reviewed more frequently. It follows that there is a higher chance of detecting an exacerbation in this group. By setting a sufficiently high bar, that is - an exacerbation deemed severe enough to require IVABs - we aim to prevent over-ascertainment of mild exacerbations in the intervention group. The use of IVABs is unlikely to be missed in either trial arm, since it is administered by the CF team in an acute setting, whereas oral antibiotics from general practitioner (GP) might be underreported in the control group who are seen less frequently. Second, the use of four or more symptoms - as in the original Fuchs' criteria - is a high threshold; by comparison, our use of one or more symptoms increases sensitivity to CF symptoms. Finally, this definition is in use in modern pivotal trials [73].

\section{Data analysis}

Details of participant screening, recruitment and retention were presented in a CONSORT flow diagram. Baseline characteristics were presented by treatment arm and overall.

The total number of exacerbations by participant and by treatment arm were presented. As this was a pilot study, definitive comparisons of interventions were not undertaken, however point estimates of effect and their 95\% confidence intervals were reported for primary and secondary clinical outcomes [72, 74]. A primary effectiveness analysis was conducted on the primary clinical outcome using a negative binomial model and adjusting for number of IV days in the previous 12 months and site. Incidence rate ratio (IRR) and 95\% confidence intervals were presented.

Adjusted mean difference in Forced Expiratory Volume (FEV-1) percent predicted was estimated using a multiple linear regression model adjusting for baseline and site. A full statistical methods and descriptive statistics for all 
Table 1 Secondary clinical outcomes

Secondary outcomes

Body Mass Index (BMI).

Forced expiratory volume in $1 \mathrm{~s}$ (FEV1): standardised spirometry as a measure of condition severity [100].

EuroQol EQ-5D-5 L: generic health status measure for health economic analysis [101].

The Patient Activation Measure (PAM-13): assessment of patient knowledge, skill, and confidence for self-management [102]. Elements of the PAM-13 map to logic model constructs \#29 and \#30.

Confusion, Hubbub, and Order Scale (CHAOS 6-item): measure of life chaos [103]. Elements of the CHAOS-6 map to logic model construct \#32.

Medication Adherence Data-3 items (MAD-3). Bespoke questionnaire adapted from the Medication Adherence Reporting Scale [104]:

1. I forget to take my nebuliser treatment (Always/Often/Sometimes/ Rarely/Never)

2. I take fewer nebuliser treatments than my doctor recommends

(Always/Often/ Sometimes/Rarely/Never)

3. I decide to skip one or more of my nebuliser treatments (Always/

Often/Sometimes/Rarely/Never)

Maps to logic model construct \#28.

Self-Report Behavioural Automaticity Index (SRBAI) [105]. Maps to logic model construct \#31.

Cystic Fibrosis Questionnaire-Revised (CFQ-R): disease specific health-related quality of life instrument [106].

The Patient Health Questionnaire depression scale (PHQ-8): severity measure for depressive disorders [107].

The General Anxiety Disorder 7-item anxiety scale (GAD-7): severity measure for anxiety [108];

The Capability Opportunity Motivation Behaviour Beliefs Questionnaire (COM- BMQ), incorporating the validated self-report Beliefs about Medicines Questionnaire - specific (Nebuliser adherence) (BMQ 21item) [109], customised by the team to identify perceived necessities and concerns for nebuliser treatment. Elements of the COM-BMQ map to logic model constructs \#7, \#29 and\#33.

Project-specific items on belief, intention and confidence

Subjective adherence single question: self-report estimate of adherence as a percentage. Maps to logic model construct \#28.

Self-reported problems: identification of capability and opportunity barriers to nebuliser adherence. Maps to logic model construct \#33.

Concomitant medications: bespoke instrument, designed for this research project.

Resource use form (inpatient IV days; routine clinic visits; unscheduled outpatient contacts; unscheduled inpatient stays).

Prescription: a monthly prescription check to both check for data transfer to CFHealthHub and review for an indication that the prescription has changed

Objective Adherence to prescribed medication

Any treatment with IV antibiotics

secondary outcomes can be found in Additional file 4 . Trial statisticians remained blind until database freeze, the point where all data had been input and all known queries resolved. The intention-to-treat population (primary analysis set) included all participants for whom consent was obtained and who were randomised to treatment, regardless of whether they received the intervention or not [75]. We tested using prescription and nebuliser data to calculate the total number of doses and simple unadjusted adherence [39]. Weekly numerator-adjusted normative adherence [39] was calculated and a mean by treatment arm was calculated and presented as a line graph. Data collected beyond the final intervention session, until 30th April enabled us to understand whether flat-lining of the adherence charts resulted from a technical fault or non-adherence to prescribed medication. The number of adverse events (AEs) and serious adverse events (SAEs) was presented by treatment arm.

Statistical analysis was performed using $\mathrm{R}$ version 3.4.1 statistical software [76].

A Framework analysis [77] of the semi-structured interviews was undertaken to investigate the acceptability of trial procedures for participating site staff and patients [78]; additionally, we investigated whether control participants had been "contaminated" by knowledge of, or receipt of the intervention [79].

\section{Approach taken to modifying research procedures}

Modifications, arising from interviews, reports recorded on our log of problems, management group and patient and public involvement (PPI) meetings, were categorised to do with: the software platform; the manual and training; and, the RCT procedures. Based on a modified version of the approach taken by Bugge, we tabulated issues and solutions [29]. We regularly reviewed priorities for development of the digital platform using a system known as, "Must have, Should have, Could have, and Won't have but would like" (MoSCoW) [28], frequently used in agile software development $[52,53]$.

\section{Patient and public involvement}

The Patient and Public Involvement (PPI) Group were recruited through leaflets placed in CF units, advertising on the People in Research website and snowballing. They teleconferenced to prevent cross-infection between PWCF [80] and provided feedback on intervention data-sharing policies, usability and presentation of the website/user-guide; they piloted participant information materials and one person also provided input on the trial protocol and interview guides (Additional file 1).

\section{Ethical approval}

The study received approval from London Brent Research Ethics Committee (16/LO/0356). The funder was not involved in the trial design, patient recruitment, data collection, analysis, interpretation, or presentation, writing or editing of the report, or the decision to submit for publication. The corresponding author had full access to 
all the data in the study and had final responsibility for the decision to submit for publication.

\section{Results}

\section{Recruitment}

We recruited between 23rd June and 30 September 2016. Overall, 430 PWCF were reviewed for eligibility (Fig. 3). Of these, 135 were eligible, 95 (70\%) successfully contacted and $64(67 \%)$ of those contacted consented; $100 \%$ of the intended sample size were therefore recruited, exceeding the $75 \%$ target. A total of 33 participants were allocated to the intervention group and 31 to the control group.

\section{Participant characteristics}

Participants entering the study had a median age of 27 and $56 \%$ were male (Table 2). Most participants were from average (25\%), low (23\%) or least deprived (23\%) areas of deprivation. Mean baseline FEV1 percent predicted was 57.3. Full baseline characteristics tables can be found in Additional file 4.

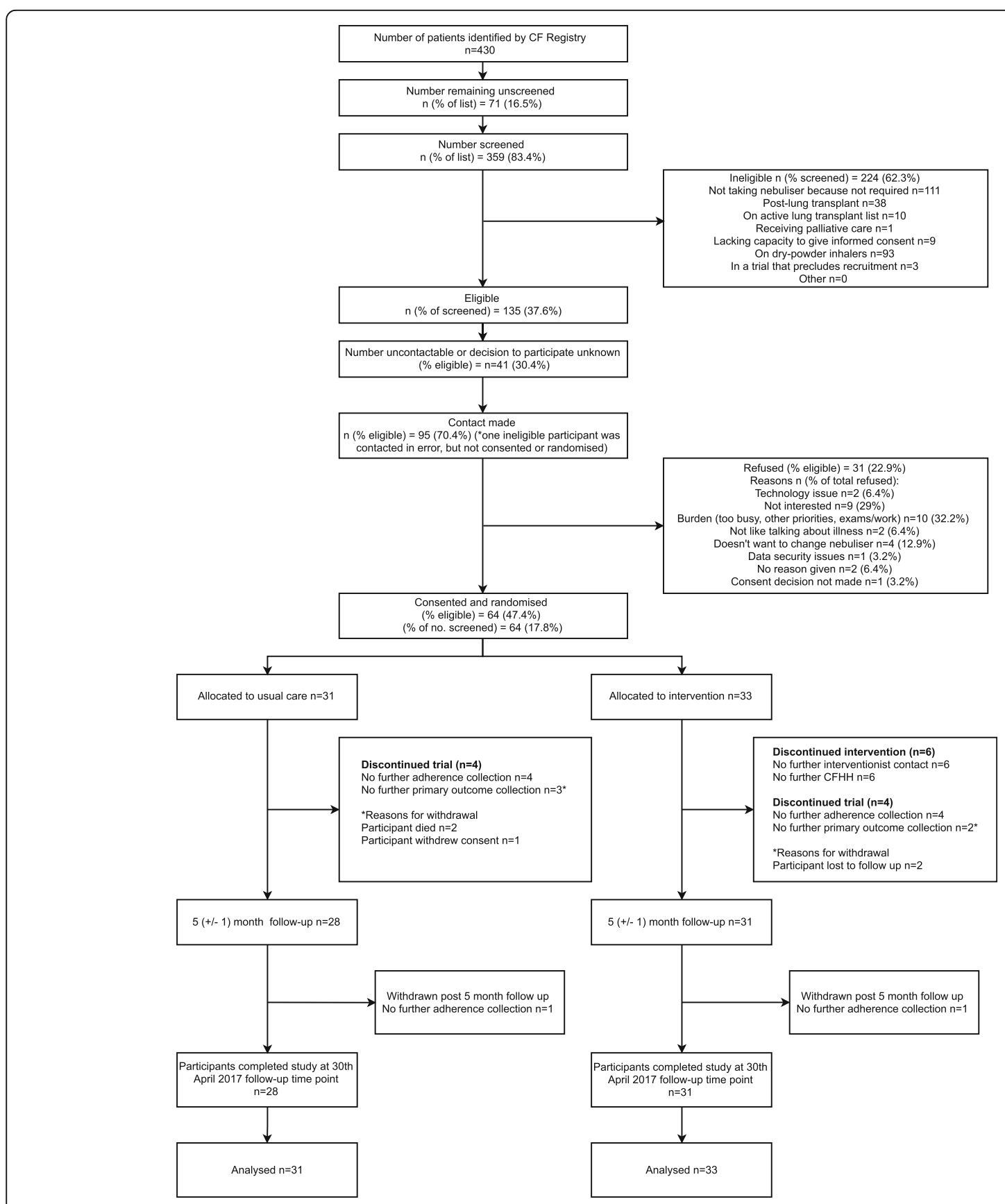

Fig. 3 Participant flow 
Table 2 Baseline characteristics by treatment arm

\begin{tabular}{llll}
\hline & Intervention & Control & Overall \\
\hline Age & 33 & 31 & 64 \\
$\mathrm{n}$ & $31.6(13.3)$ & $27.8(8.9)$ & $29.7(11.5)$ \\
Mean (SD) & $28(21,37)$ & $26(20,34)$ & $27(21,36)$ \\
Median (IQR) & & & \\
Sex & $18(55 \%)$ & $18(58 \%)$ & $36(56 \%)$ \\
Male & $15(45 \%)$ & $13(42 \%)$ & $28(44 \%)$ \\
Female & & & $7(11 \%)$ \\
Socioeconomic Status & & $1(3 \%)$ & $11(17 \%)$ \\
Most deprived & $6(18 \%)$ & $7(23 \%)$ & $16(25 \%)$ \\
High deprivation & $4(12 \%)$ & $8(26 \%)$ & $15(23 \%)$ \\
Average & $8(24 \%)$ & $9(29 \%)$ & $15(23 \%)$ \\
Low deprivation & $6(18 \%)$ & $6(19 \%)$ & 64 \\
Least deprived & $9(27 \%)$ & & $49.6(41.9,76.7)$ \\
FEV1\% Predicted & & 31 & $61.4(22.7)$ \\
$\mathrm{n}$ & 33 & $53.4(43,80)$ & \\
Mean (SD) & $53.4(19.4)$ & $49.2(39.4,61.9)$ & \\
Median (IQR) & & &
\end{tabular}

\section{Retention}

At study completion on 30th April 2017, 60 (94\%: Intervention $=32$, Control $=28$ ) participants contributed exacerbation data, therefore exceeding the target $85 \%$ retention rate with respect to primary outcome data contribution. A total of 57 (89\%: Intervention $=30$, Control $=27$ ) contributed $\mathrm{FEV}_{1}$ data; 59 (92\%: Intervention $=31$, Control = 28) contributed follow-up questionnaire data and 48 (75\%: Intervention $=24$, Control $=24)$ contributed $5( \pm 1)$ months of adherence data (Fig. 4). Two participants died (not related to RCT participation), one withdrew research consent, two were lost to follow-up, and two withdrew from adherence data collection $($ Intervention $=1$, Control $=1$ ).

\section{Quality of primary clinical outcome data}

There were 79 data collection sheets completed providing information on, the expected primary outcome for the full trial, in those followed up for $5( \pm 1)$ months; 60 of the data collection sheets identified episodes that fulfilled the primary outcome with at least 1 Fuchs' symptom and treatment with IV antibiotics. A total of 18 sheets were completed for episodes not treated with IVABs, and one episode treated with IVAB did not meet any of the modified Fuchs' criteria. Of 60 that were included in the analysis set, 35 exacerbations occurred in intervention participants, 25 in control participants (see Discussion). 33 participants experienced at least 1 exacerbation (Intervention $=19(60 \%)$, Control $=14(50 \%)$ ). Adjusted IRR was 1.12 (95\% CI: 0.66-1.94) indicating no difference between treatment arms.

\section{Other key clinical outcomes}

Adjusting for baseline and site, there was a between-group difference of $5 \%$ (95\% CI -2 to $12 \%$ ) in $\mathrm{FEV}_{1}$ percent predicted (Table 3). Figure 4 indicates a small difference across treatments arms in numerator adjusted mean weekly adherence during the study with the overall difference between treatment arms for the whole study period being $10 \%$ (95\% CI: -5.2 to 25.2 ), greater in the intervention arm. Further details of secondary clinical outcomes are available in Additional file 4. A total of eight adverse events occurred; seven participants (11\%) had at least one adverse event, of which five were serious adverse events, none related to the intervention. Of the five SAEs, 3/33 (9\%) were in the intervention arm and $2 / 31$ (7\%) were in the control arm. The 2 SAEs in the control arm were deaths; there were no deaths in the intervention arm but 2 hospitalisations and 1 persistent or significant disability/ incapacity.

\section{Acceptability and robustness of the trial procedures}

The information sheet was described as 'wordy' and questionnaires repetitive; otherwise, participants found research procedures acceptable. Interventionists confirmed that they had no access to adherence data for control patients, as required by trial procedures. MDT members said a lack of resources and training precluded contamination. There was no systematic strategy to involve the wider CF team in the use of the adherence data to support care and most data sharing was via the interventionist. This was partly a conscious strategy to avoid contamination of the control subjects. Aside from the new nebuliser and 2net Hub, control participants viewed their care and approach to self-management as unaffected, although one admitted making an effort to adhere because of the collection of adherence data.

\section{Modifications to research procedures}

Additional file 5 documents 10 technical changes made, in relation to RCT procedures, to CFHH $(n=1)$, IT infrastructure $(n=1)$, and trial procedures $(n=8)$. To prevent adherence data flatlines, nebulisers (\#4) and 2net Hubs (\#5) are now paired at the factory. In the feasibility study, a focus on RCT recruitment targets gave interventionists inadequate time to deliver review visits (\#18, $\# 24$ ), critical for updating personalised action plans (\#25) and updating coping plans (\#26). Therefore the full-scale trial will also have a longer pro rata participant accrual window. As there was inconsistency in completion of the case report form for exacerbations (primary clinical outcome), changes have been made to training and the case report forms for the main trial. Namely, the modified form records if the clinical team considered there to be a need for IVABs, whether these were 


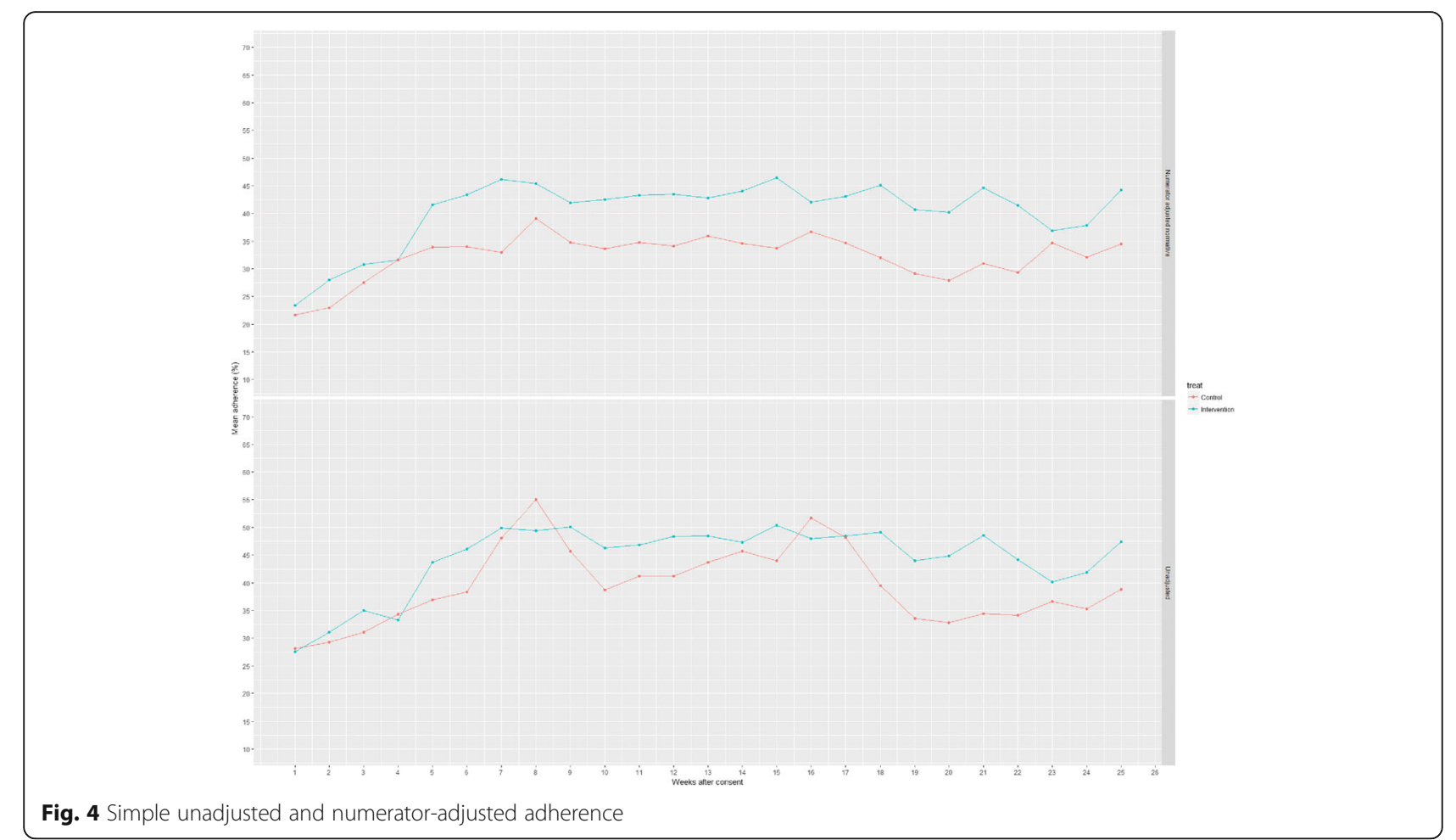

accepted or not and subsequently whether any Fuchs' criteria were met. Fuchs' criteria are assessed regardless of whether IVABs were accepted by the patient.

\section{Discussion}

The pilot RCT recruited well; in particular, recruitment to the pilot was very high compared to other clinical CF trials, illustrating the importance and relevance of adherence to CF patients [81]. Participant retention and study procedures were satisfactory, with no obvious contamination in the control arm.

In $24 \%$ of cases where clinicians competed the case report form for an exacerbation, the criteria for this primary clinical endpoint were not met (see Results | Quality of primary clinical outcome data). This may have been, as in other studies [82, 83], instances in which a clinician identified the clinical need for IVAB but patients chose treatment with oral antibiotics. There is no universally-agreed definition of an exacerbation $[84,85]$. In our study, the modified Fuchs' criteria provided a relatively objective assessment of clinical need; adding treatment with IVABs ensured that only clinically severe episodes are analysed. This definition goes some way to decreasing ascertainment bias arising when closer monitoring identifies less serious cases [84, 85], with less impact on the health system than IVAB, and allows adjustment for baseline adherence [86] via routinely collected data. However, as adherence improves, patients may be more willing to accept IVABs for exacerbations, which could make ascertainment bias more marked. There was no

Table 3 Results of clinical outcomes

\begin{tabular}{|c|c|c|c|c|c|c|c|}
\hline & & \multicolumn{2}{|c|}{ Intervention } & \multicolumn{4}{|c|}{ Control } \\
\hline & & $n$ & Median (IQR) & $n$ & Median (IQR) & IRR & $95 \% \mathrm{Cl}$ \\
\hline \multirow{3}{*}{$\begin{array}{l}\text { Number of exacerbations treated with IV antibiotics } \\
\text { with at least } 1 \text { Fuchs' criteria in a } 6 \text { month period } \\
\text { (primary outcome definition) }\end{array}$} & Unadjusted & 32 & $1(0,2)$ & 28 & $0.5(0,2)$ & 1.22 & $(0.69,2.21)$ \\
\hline & Adjusted $^{a}$ & & & & & 1.12 & $(0.66,1.94)$ \\
\hline & & $n$ & Mean (SD) & $n$ & Mean (SD) & Mean Diff & $95 \% \mathrm{Cl}$ \\
\hline \multirow[t]{2}{*}{ FEV1 percent predicted } & Unadjusted & 30 & $54.2(21.1)$ & 27 & $59(23.9)$ & -4.8 & $(-17,7.1)$ \\
\hline & Adjusted $^{\mathrm{b}}$ & & & & & 5 & $(-2,12)$ \\
\hline
\end{tabular}

${ }^{a}$ Adjusted for number of IV days in previous 12 months and site 
difference in the rate of exacerbations/primary outcome between treatment arms however the study was not powered to detect an effect and was designed to assess feasibility and the quality of the primary outcome data as described above. Changes to CRF exacerbation forms for the full-scale RCT will capture the number of cases in which exacerbation criteria were met but IVABs were refused by the patient, allowing detection of any ascertainment bias. To better understand variation in adherence over time, the full-scale trial will use differences in mean group adherence over time, as expressed in Fig. 4, in addition to pre/post measurements, which can miss changes in adherence over the course of the trial (\#35). Future intervention research should consider the use of continuous data to avoid missing patterns of adherence behaviour between assessment timepoints.

Evidence that patient access to data improves health outcomes or is cost-effective is generally poor and lacks information about context and implementation [87, 88]. The full-scale RCT of our modified intervention at 19 UK centres (ISRCTN55504164) will provide high quality evidence on the subject in 2020, with further process evaluation and health-economic modelling. The problem of how to embed routine use of adherence data by healthcare professionals [89-93] is the subject of the CFHealthHub Data Observatory (ISRCTN14464661). This quality improvement project, onto which pilot sites have now transitioned, will eventually host sites from the full-scale RCT. The data it collects will be used to develop theory and practical guidance about the collaborative use of adherence data that is generalisable to multiple contexts [94, 95], with the aim of improving patient care and using NHS resources more efficiently [96]. The Observatory will act as a platform for efficient trials [97, 98]. Shared processes and improvement activities should increase the capacity and success of participating cystic fibrosis clinical research teams [99].

\section{Conclusions}

We have developed a theory-based complex intervention to help PWCF adhere to their medication. The pilot trial observed a recruitment rate of eight participants per centre per month, with acceptable levels of attrition. The findings reported in this paper give high levels of confidence that, with improved trial procedures, a full-scale trial is feasible.

\section{Additional files}

Additional file 1: Study protocol and interview guides. (PDF $2311 \mathrm{~kb}$ )

Additional file 2: CONSORT checklist. (DOC $226 \mathrm{~kb}$ )

Additional file 3: Release notes for 59 software development cycles between June 2015 and June 2017. (DOCX 17 kb)
Additional file 4: Statistical methods, outcomes and estimation. (DOCX $272 \mathrm{~kb}$ )

Additional file 5: Changes to intervention and trial procedures. (DOCX $22 \mathrm{~kb}$ )

\section{Acknowledgements}

We would like to thank the trial participants who offered us their time. We gratefully acknowledge the clerical and other input of Helen Wakefield, Heather Dakin, Katie Shore and Louise Turner, trial support officers.

Professor Walters is a National Institute for Health Research (NIHR) Senior Investigator. The views expressed in this article are those of the author(s) and not necessarily those of the NHS, the NIHR, or the Department of Health and Social care.

\section{Funding}

This report presents independent research funded by the NIHR under its Grants for Applied Research Programme (Grant Reference Number RP-PG1212-20015). The views and opinions expressed by authors in this publication are those of the authors and do not necessarily reflect those of the NHS, the $\mathrm{NIHR}$, Medical Research Council (MRC), Central Commissioning Facility (CCF), the Programme Grants for Applied Research Programme, or the Department of Health and Social Care.

\section{Availability of data and materials}

Requests for further data not available in this publication can be directed at Sheffield Clinical Trials Research Unit. Email: ctru@sheffield.ac.uk Tel: 0114 2,220,866.

\section{Authors' contributions}

DH (Assistant Director, CTRU), SD (Research Associate) and LM (Statistician), together produced the first draft of the report. The following conceived of or designed the work: MW (Consultant Respiratory Physician), A O'C (Professor of Health Services Research), SW2 (Professor of Medical Statistics and Clinical Trials), MA1 (Professor of Health Psychology), MH (Physiotherapist), JB (Professor of Physiotherapy), JA (Professor of Health Informatics), DB (Patient and Public Involvement Representative) and DH. The following were involved in the acquisition of data for the work: JN (Consultant in Respiratory Medicine), MA2 (Consultant in Respiratory Medicine), JD (Consultant in Respiratory Medicine), SD, MA1, CM, HC, AS, AS (Research Associate), SK (Research Associate), MH and PW (mHealth Applications Manager). The following were involved in the analysis of data: $D H, S D, A O^{\prime} C, D B, A S, S K$, MA1, LM, SW1 (Data Manager). DH, SD, MA1, LM, SW1, CM, HC, MH, JB, JN, $M A 2, J D, D B, S W 2, A O^{\prime} C, M J W$, were involved in the interpretation of data for the work. All authors were involved in the final approval of the version to be published. All authors agree to be accountable for all aspects of the work in ensuring that questions related to the accuracy or integrity of any part of the work are appropriately investigated and resolved.

\section{Ethics approval and consent to participate}

Written informed consent was obtained prior to participation. The study received ethical approval from the London Brent Research Ethics Committee (16/LO/O356).

\section{Consent for publication \\ Not applicable.}

\section{Competing interests}

Martin Wildman received funding from Zambon and support from Philips Respironics for the early intervention development work. This has not had any direct influence on the feasibility study reported here. In addition, Martin Wildman has worked with Pari to carry out studies using the e-track. This has not had any direct influence on the feasibility study reported here. The University of Manchester software team received funding from Pari to create a medication reporting component within the CFHealthHub software. This has not had any direct influence on the feasibility study reported here.

The other authors declare that they have no competing interests.

\section{Publisher's Note}

Springer Nature remains neutral with regard to jurisdictional claims in published maps and institutional affiliations. 


\section{Author details}

${ }^{1}$ Clinical Trials Research Unit, University of Sheffield, Regent Court, 30 Regent Street, Sheffield S1 4DA, UK. ${ }^{2}$ School of Health and Related Research, Regent Court, 30 Regent Street, Sheffield S1 4DA, UK. ${ }^{3}$ Centre for Behavioural Science and Applied Psychology, Sheffield Hallam University, Collegiate Crescent, Sheffield S10 2BQ, UK. ${ }^{4}$ Sheffield Adult Cystic Fibrosis Unit Sheffield Teaching Hospitals NHS Foundation Trust, Northern General Hospital, Herries Road, Sheffield S5 7AU, UK. ${ }^{5}$ Centre for Experimental Medicine, School of Medicine, Dentistry and Biomedical Sciences, Queen's University, 97 Lisburn Road, Belfast BT9 7BL, UK. ${ }^{6}$ Wessex Adult Cystic Fibrosis Service, University Hospital Southampton NHS Foundation Trust, Tremona Road, Southampton, Hampshire SO16 6YD, UK. Wolfson Cystic Fibrosis Centre, Nottingham University Hospitals NHS Trust, City Hospital, Hucknall Road, Nottingham NG5 1PB, UK. ${ }^{8}$ Health eResearch Centre - Farr Institute, Division of Imaging, Informatics and Data Sciences, School of Health Sciences, Faculty of Biology, Medicine and Health, The University of Manchester, Manchester Academic Health Science Centre, Manchester, UK.

\section{Received: 6 July 2018 Accepted: 20 March 2019}

\section{Published online: 11 April 2019}

\section{References}

1. Jeffery A, Charman S, Cosgriff R, Carr S. UK Cystic Fibrosis Registry Annual Data Report 2016. London: Cystic Fibrosis Trust; 2017.

2. Cystic Fibrosis Foundation. Annual Data Report 2016 Cystic Fibrosis Foundation patient registry. Bethesda, Maryland: Cystic Fibrosis Foundation Patient; 2017.

3. European Cystic Fibrosis Society. ECFS patient registry annual data report. Karup: European Cystic Fibrosis Society; 2013.

4. Ahern S, Sims G, Tacey M, Esler M, Oldroyd J, Dean J, et al. The Australian Cystic Fibrosis Data Registry Annual Report, 2015. Monash University, Department of Epidemiology and Preventive Medicine, October 2017, report no 18. Melbourne, Victoria: Australian Cystic Fibrosis Data Registry. p. 2017.

5. Cystic Fibrosis Canada. The Canadian CF Registry 2016 Annual data report. Toronto: Cystic Fibrosis Canada; 2017.

6. Mowat A. Why does cystic fibrosis display the prevalence and distribution observed in human populations? Curr Pediatr Res. 2017;21(1):164-71.

7. Southern KW, Barker PM, Solis-Moya A, Patel L. Macrolide antibiotics for cystic fibrosis. In: Southern KW, editor. Cochrane database of systematic reviews. Chichester: John Wiley \& Sons, Ltd; 2011.

8. Ramsey BW, Davies J, McElvaney NG, Tullis E, Bell SC, Dřevínek P, et al. A CFTR Potentiator in patients with cystic fibrosis and the G551D mutation. N Engl J Med. 2011;365(18):1663-72.

9. McCoy KS, Quittner AL, Oermann CM, Gibson RL, Retsch-Bogart GZ, Montgomery AB. Inhaled aztreonam lysine for chronic airway Pseudomonas aeruginosa in cystic fibrosis. Am J Respir Crit Care Med. 2008;178(9):921-8

10. Ryan G, Mukhopadhyay S, Singh M. Nebulised anti-pseudomonal antibiotics for cystic fibrosis. In: Ryan G, editor. Cochrane database of systematic reviews. Chichester: John Wiley \& Sons, Ltd; 2003.

11. Jones AP, Wallis C. Dornase alfa for cystic fibrosis. In: Jones AP, editor. Cochrane database of systematic reviews. Chichester: John Wiley \& Sons, Ltd; 2010.

12. Wark P, McDonald VM. Nebulised hypertonic saline for cystic fibrosis. In: Wark P, editor. Cochrane database of systematic reviews. Chichester: John Wiley \& Sons, Ltd; 2009.

13. Ryan $\mathrm{G}$, Singh M, Dwan K. Inhaled antibiotics for long-term therapy in cystic fibrosis. Cochrane Database Syst Rev. 2011;3:CD001021.

14. Daniels T, Goodacre L, Sutton C, Pollard K, Conway S, Peckham D. Accurate assessment of adherence: self-report and clinician report vs electronic monitoring of nebulizers. Chest. 2011;140(2):425-32.

15. Eakin MN, Bilderback A, Boyle MP, Mogayzel PJ, Riekert KA. Longitudinal association between medication adherence and lung health in people with cystic fibrosis. J Cyst Fibros. 2011;10(4):258

16. Briesacher BA, Quittner AL, Saiman L, Sacco P, Fouayzi H, Quittell LM, et al. Adherence with tobramycin inhaled solution and health care utilization. BMC Pulm Med. 2011;11(1):5.

17. Smyth A, Lewis S, Bertenshaw C, Choonara I, McGaw J, Watson A. Casecontrol study of acute renal failure in patients with cystic fibrosis in the UK. Thorax. 2008;63(6):532-5.

18. Mayer-Hamblett N, Rosenfeld M, Emerson J, Goss CH, Aitken ML. Developing cystic fibrosis lung transplant referral criteria using predictors of 2-year mortality. Am J Respir Crit Care Med. 2002;166(12):1550-5.
19. Shiers D, Rafi I, Cooper S, Holt R. 2014 Update (with acknowledgement to the late Helen Lester for her contribution to the original 2012 version) positive Cardiometabolic health resource: an intervention framework for patients with psychosis and schizophrenia. R Coll Psychiatr. 2014:London.

20. Quittner AL, Zhang J, Marynchenko M, Chopra PA, Signorovitch J, Yushkina $Y$, et al. Pulmonary medication adherence and health-care use in cystic fibrosis. Chest. 2014;146(1):142-51.

21. Narayanan S, Mainz JG, Gala S, Tabori H, Grossoehme D. Adherence to therapies in cystic fibrosis: a targeted literature review. Expert Rev Respir Med. 2017;11(2):129-45.

22. Bush A, Simmonds NJ. Hot off the breath: 'I've a cost for' - the 64 million dollar question: Table 1. Thorax. 2012;67:382-4. https://doi.org/10.1136/ thoraxjnl-2012-201798.

23. Angelis A, Kanavos P, López-Bastida J, Linertová R, Nicod E, Serrano-Aguilar $P$, et al. Social and economic costs and health-related quality of life in noninstitutionalised patients with cystic fibrosis in the United Kingdom. BMC Health Serv Res. 2015;15:428. https://doi.org/10.1186/s12913-015-1061-3.

24. Hoo ZH, Wildman MJ, Curley R, Walters SJ, Campbell MJ. Rescue therapy within the UK cystic fibrosis registry: an exploration of predictors of intravenous antibiotic use amongst adults with CF. Respirology. 2018;23:190-7. https://doi. org/10.1111/resp.13174.

25. Tappenden P, Sadler S, Wildman M. An Early Health Economic Analysis of the Potential Cost Effectiveness of an Adherence Intervention to Improve Outcomes for Patients with Cystic Fibrosis. Pharmacoeconomics. 2017;35: 647-59. https://doi.org/10.1007/s40273-017-0500-x.

26. Horne RW, Barber N, Elliot R, Morgan M. Concordance, Adherance and compliance in medicine taking: a conceptual map and research priorities. National Co-Ordinating Centre for NHS Service Delivery and Organisational R\&D (NCCSDO). 2005.

27. James Lind Alliance. Priority Setting Partnership: Cystic Fibrosis. 2017.

28. Clegg D, Barker R. Case method fast-track: a RAD approach. Boston, MA: Addison-Wesley; 1994.

29. Bugge C, Williams B, Hagen S, Logan J, Glazener C, Pringle S, et al. A process for decision-making after pilot and feasibility trials (ADePT): development following a feasibility study of a complex intervention for pelvic organ prolapse. Trials. 2013;14(1):353.

30. Eldridge SM, Chan CL, Campbell MJ, Bond CM, Hopewell S, Thabane L, et al. CONSORT 2010 statement: extension to randomised pilot and feasibility trials. Pilot Feasibility Stud. 2016;2(1):64.

31. Nelson EC, Godfrey MM, Batalden PB, Berry SA, Bothe AE, McKinley KE, et al. Clinical microsystems, part 1. The building blocks of health systems. Jt Comm J Qual Patient Saf. 2008;34(7):367-78.

32. Mintzberg H. The strategy concept I: five Ps for strategy. Calif Manag Rev. 1987:30(1):11-24.

33. Godfrey MM, Foster TC, Johnson JK, Harrison S, Wildman MJ. Developing high-performing microsystems. In: Nelson EC, Batalden PB, Godfrey MM, editors. Quality by design, 2nd edition. San Francisco: Jossey-Bass; .

34. Jones S, Curley R, Wildman M, Morton RW, Elphick HE. Interventions for improving adherence to treatment in cystic fibrosis. In: Jones S, editor. Cochrane database of systematic reviews. Chichester: John Wiley \& Sons, Ltd; 2015.

35. Jones S, Curley R, Wildman M. 345 Systematic review of qualitative studies investigating barriers to adherence in patients with cystic fibrosis using framework analysis structured by a conceptual framework of behaviour change. J Cyst Fibros. 2013;12(Suppl 1):S136.

36. Barach $\mathrm{P}$, Johnson JK. Understanding the complexity of redesigning care around the clinical microsystem. Qual Saf Heal Care. 2006;15(suppl_1):110-6.

37. Hoo Z, Gardner B, Curley R, Wildman M. Part I : Understanding the variation in adherence with nebulised treatment in Cystic Fibrosis. J Improv Sci. 2013; 9(January):1-10.

38. Wildman MJ, Hoo ZH. Moving cystic fibrosis care from rescue to prevention by embedding adherence measurement in routine care. Paediatr Respir Rev. 2014;15(S1):16-8.

39. Hoo ZH, Curley R, Campbell MJ, Walters SJ, Hind D, Wildman MJ. Accurate reporting of adherence to inhaled therapies in adults with cystic fibrosis: methods to calculate normative adherence. Patient Prefer Adherence. 2016;887.

40. Milne A, Rose C, Thornton S, Curley R, Hoo ZH, Wildman M. 275 understanding barriers to weight gain, nebuliser use and exercise in CF. J Cyst Fibros. 2014;13:S118.

41. Jones S, Babiker N, Gardner E, Royle J, Curley R, Hoo ZH, et al. Promoting adherence to nebulized therapy in cystic fibrosis: poster 
development and a qualitative exploration of adherence. Patient Prefer Adherence. 2015:9:1109-20.

42. Arden MA, Drabble SJ, O'Cathain A, Hutchings M, Wildman M. WS16.1 ACtiF study: understanding adherence to nebuliser treatment in adults with cystic fibrosis using the theoretical domains framework. J Cyst Fibros. 2016;15:S26.

43. Cane J, O'Connor D, Michie S. Validation of the theoretical domains framework for use in behaviour change and implementation research. Implement Sci. 2012;7:37.

44. French SD, Green SE, O'Connor DA, McKenzie JE, Francis JJ, Michie S, et al. Developing theory-informed behaviour change interventions to implement evidence into practice: a systematic approach using the Theoretical Domains Framework. Implement Sci. 2012;7(1):38.

45. Atkins L, Francis J, Islam R, O'Connor D, Patey A, Ivers N, et al. A guide to using the Theoretical Domains Framework of behaviour change to investigate implementation problems. Implement Sci. 2017;12(1):77.

46. Michie $S$, van Stralen MM, West R. The behaviour change wheel: a new method for characterising and designing behaviour change interventions. Implement Sci. 2011;6(1):42.

47. Michie S. Implementation science: understanding behaviour change and maintenance. BMC Health Serv Res. 2014;14:09. https://doi.org/10.1186/ 1472-6963-14-S2-09.

48. Michie S, Atkins L, West R. The behaviour change wheel: a guide to designing interventions. Sutton: Silverback Publishing; 2014.

49. Bandura A. Social cognitive theory: an agentic perspective. Annu Rev Psychol. 2001;52(1):1-26

50. Carver CS, Scheier MF. Control theory: a useful conceptual framework for personality-social, clinical, and health psychology. Psychol Bull. 1982;92(1): 111-35

51. Sadler S, Wildman M, Tappenden P. 267 cost-effectiveness of a complex adherence intervention to improve prevention in cystic fibrosis by empowering effective self-management: an exploratory health economic evaluation using UK registry data. J Cyst Fibros. 2016;15:S119-20.

52. Bittner K, Spence I. Use case modeling. Boston, MA: Addison-Wesley Professional; 2002

53. Larman C. Agile and iterative development: a Manager's guide. Boston, MA: Addison-Wesley; 2004

54. Morera EP, de la Torre DI, Garcia-Zapirain B, López-Coronado M, Arambarri J. Security recommendations for mHealth apps: elaboration of a Developer's guide. J Med Syst. 2016;40(6):152.

55. Silva BMC, Rodrigues JJPC, de la Torre DI, López-Coronado M, Saleem K. Mobile-health: a review of current state in 2015. J Biomed Inform. 2015;56: 265-72.

56. Langer SG. Cyber-security issues in healthcare information technology. J Digit Imaging. 2017;30(1):117-25.

57. Bennett K, Bennett AJ, Griffiths KM. Security considerations for e-mental health interventions. J Med Internet Res. 2010;12(5):e61.

58. Norman DA, Draper SW. User centered system design : new perspectives on human-computer interaction. L. Erlbaum Associates; 1986.

59. Arnowitz J, Arent M, Berger N. Effective prototyping for software makers. London: Elsevier; 2010

60. Böhmann T, Leimeister JM, Möslein K. Service systems engineering. Bus Inf Syst Eng. 2014;6(2):73-9.

61. Venkatesh V, Morris MG, Davis GB, Davis FD. User acceptance of information technology: toward a unified view. MIS Q. 2003;27(3):425-78.

62. Volpp KG, Terwiesch C, Troxel A B, Mehta S, Asch D A. Making the RCT more useful for innovation with evidence-based evolutionary testing. Healthc (Amsterdam, Netherlands). 2013;1(1-2):4-7.

63. Asch DA, Rosin R. Innovation as discipline. Not Fad N Engl J Med. 2015; 373(7):592-4.

64. Patrick K, Hekler EB, Estrin D, Mohr DC, Riper H, Crane D, et al. The pace of technologic change: implications for digital health behavior intervention research. Am J Prev Med. 2016;51(5):816-24

65. Hoddinott P. A new era for intervention development studies. Pilot Feasibility Stud. 2015;1(1):36.

66. Levati S, Campbell P, Frost R, Dougall N, Wells M, Donaldson C, et al. Optimisation of complex health interventions prior to a randomised controlled trial: a scoping review of strategies used. Pilot Feasibility Stud. 2016;2(1):1-17.

67. Borrelli B, Sepinwall D, Ernst D, Bellg AJ, Czajkowski S, Breger R, et al. A new tool to assess treatment fidelity and evaluation of treatment fidelity across 10 years of health behavior research. J Consult Clin Psychol. 2005;73(5):852-60.
68. Bellg AJ, Borrelli B, Resnick B, Hecht J, Minicucci DS, Ory M, et al. Enhancing treatment fidelity in health behavior change studies: best practices and recommendations from the $\mathrm{NIH}$ behavior change consortium. Health Psychol. 2004;23(5):443-51.

69. Lancaster GA, Dodd S, Williamson PR. Design and analysis of pilot studies: recommendations for good practice. J Eval Clin Pract. 2004;10(2):307-12

70. Arain M, Campbell MJ, Cooper CL, Lancaster GA. What is a pilot or feasibility study? A review of current practice and editorial policy. BMC Med Res Methodol. 2010;10(1):67

71. Eldridge S, Bond C, Campbell M, Lancaster G, Thabane L, Hopwell S. Definition and reporting of pilot and feasibility studies. Trials. 2013;14(Suppl 1):018.

72. Thabane L, Ma J, Chu R, Cheng J, Ismaila A, Rios LP, et al. A tutorial on pilot studies: the what, why and how. BMC Med Res Methodol. 2010;10(1):1+.

73. Ratjen F, Durham T, Navratil T, Schaberg A, Accurso FJ, Wainwright C, et al. Long term effects of denufosol tetrasodium in patients with cystic fibrosis. J Cyst Fibros. 2012;11(6):539-49.

74. Kannan S, Gowri S. Pilot studies: Are they appropriately reported? Perspect Clin Res. 2015;6:207. https://doi.org/10.4103/2229-3485.167097.

75. Hollis $\mathrm{S}$, Campbell F. What is meant by intention to treat analysis? Survey of published randomised controlled trials. BMJ. 1999;319(7211):670-4.

76. The R Project for Statistical Computing. http://www.r-project.org. Accessed 10 Nov 2017.

77. Ritchie J, Spencer L. Qualitative data analysis for applied policy research. In: Bryman A, Burgess RG, editors. Analysing qualitative data. Routledge; 1994:173-194.

78. O'Cathain A, Hoddinott P, Lewin S, Thomas KJ, Young B, Adamson J, et al. Maximising the impact of qualitative research in feasibility studies for randomised controlled trials: guidance for researchers. Pilot Feasibility Stud. 2015;1(1):32.

79. Torgerson DJ. Contamination in trials: is cluster randomisation the answer? BMJ. 2001;322(7282):355-7.

80. Govan JR. Infection control in cystic fibrosis: methicillin-resistant Staphylococcus aureus, Pseudomonas aeruginosa and the Burkholderia cepacia complex. J R Soc Med. 2000;93(Suppl 3):40-5.

81. Hewer SL, Hickey H, Jones A, Blundell M, Smyth AR. 63 TORPEDO-CF completion of recruitment to trial of optimal regimen for eradication of new infection with Pseudomonas aeruginosa. J Cyst Fibros. 2017;16:S80.

82. Lechtzin N, Mayer-Hamblett N, West NE, Allgood S, Wilhelm E, Khan U, et al. Home monitoring of patients with cystic fibrosis to identify and treat acute pulmonary exacerbations. elCE study results. Am J Respir Crit Care Med. 2017:196(9):1144-51.

83. Somayaji R, Lechtzin N, Ramos K, Hamblett N, West N, Allgood S, et al. Lung function recovery in cystic fibrosis following a pulmonary exacerbation treated with intravenous and oral antibiotics: analysis of the elCE trial. Pediatr Pulmonol. 2017;52(S47):S214-516.

84. Ramsey BW, Boat TF. Outcome measures for clinical trials in cystic fibrosis. Summary of a Cystic Fibrosis Foundation consensus conference. J Pediatr. 1994;124(2):177-92

85. European Medicines Agency. Report of the Workshop on Endpoints for Cystic Fibrosis. 2012(November).

86. Vickers AJ, Altman DG. Statistics notes: Analysing controlled trials with baseline and follow up measurements. BMJ. 2001;323(7321):1123-4.

87. Goldzweig CL, Orshansky G, Paige NM, Towfigh AA, Haggstrom DA, MiakeLye I, et al. Electronic patient portals: evidence on health outcomes, satisfaction, efficiency, and attitudes: a systematic review. Ann Intern Med. 2013:159(10):677-87.

88. Lau AY, Arguel A, Dennis S, Liaw S-T, Coiera E. "Why Didn't it Work?" Lessons From a Randomized Controlled Trial of a Web-based Personally Controlled Health Management System for Adults with Asthma. J Med Internet Res. 2015;17(12):e283.

89. Kruse CS, Kothman K, Anerobi K, Abanaka L. Adoption factors of the electronic health record: a systematic review. JMIR Med informatics. 2016;4(2):e19.

90. Greenhalgh T, Swinglehurst D, Stones R. Rethinking resistance to "big IT": a sociological study of why and when healthcare staff do not use nationally mandated information and communication technologies. Heal Serv Deliv Res. 2014;2(39):1-86.

91. Ross J, Stevenson F, Lau R, Murray E. Factors that influence the implementation of e-health: a systematic review of systematic reviews (an update). Implement Sci. 2016;11(1):146.

92. Hennemann S, Beutel ME, Zwerenz R. Ready for eHealth? Health professionals' acceptance and adoption of eHealth interventions in inpatient routine care. J Health Commun. 2017;22(3):274-84. 
93. Harris M, Lawn SJ, Morello A, Battersby MW, Ratcliffe J, McEvoy RD, et al. Practice change in chronic conditions care: an appraisal of theories. BMC Health Serv Res. 2017;17(1):170.

94. Ovretveit J, Leviton L, Parry G. Increasing the generalisability of improvement research with an improvement replication programme. BMJ Qual Saf. 2011;20(Suppl 1):i87-91.

95. Eikey EV, Reddy MC, Kuziemsky CE. Examining the role of collaboration in studies of health information technologies in biomedical informatics: a systematic review of 25 years of research. J Biomed Inform. 2015;57:263-77.

96. National Institute for Health and Care Excellence. Medicines optimisation: the safe and effective use of medicines to enable best possible outcomes (NG5). London: NICE; 2015.

97. Relton C, Torgerson D, O'Cathain A, Nicholl J, Renton C, Torgerson D, et al. Rethinking pragmatic randomised controlled trials: introducing the "cohort multiple randomised controlled trial" design. BMJ. 2010;340(mar19 1):c1066.

98. Young-Afat DA, Verkooijen HAM, van Gils $\mathrm{CH}$, van der Velden JM, Burbach JP, Elias SG, et al. Staged-informed consent in the cohort multiple randomized controlled trial design. Epidemiology. 2016;27(3):389-92.

99. Retsch-Bogart GZ, Van Dalfsen JM, Marshall BC, George C, Pilewski JM, Nelson EC, et al. Highly effective cystic fibrosis clinical research teams: critical success factors. J Gen Intern Med. 2014;29(Suppl 3):S714-23.

100. Miller MR, Hankinson J, Brusasco V, Burgos F, Casaburi R, Coates A, et al. Standardisation of spirometry. Eur Respir J. 2005;26(2):319-38.

101. Herdman M, Gudex C, Lloyd A, Janssen M, Kind P, Parkin D, et al. Development and preliminary testing of the new five-level version of EQ-5D (EQ-5D-5L). Qual Life Res. 2011;20(10):1727-36.

102. Hibbard JH, Mahoney ER, Stockard J, Tusler M. Development and testing of a short form of the patient activation measure. Health Serv Res. 2005;40(6 Pt 1):1918-30.

103. Wong MD, Sarkisian CA, Davis C, Kinsler J, Cunningham WE. The association between life Chaos, health care use, and health status among HIV-infected persons. J Gen Intern Med. 2007;22(9):1286-91.

104. Horne R, Weinman J. Self-regulation and self-management in asthma: exploring the role of illness perceptions and treatment beliefs in explaining non-adherence to preventer medication. Psychol Health. 2002;17(1):17-32.

105. Verplanken B, Orbell S. Reflections on past behavior: a self-report index of habit Strength1. J Appl Soc Psychol. 2003;33(6):1313-30.

106. Quittner AL, Sweeny S, Watrous M, Munzenberger P, Bearss K, Gibson Nitza $\mathrm{A}$, et al. Translation and linguistic validation of a disease-specific quality of life measure for cystic fibrosis. J Pediatr Psychol. 2000;25(6):403-14

107. Kroenke K, Strine TW, Spitzer RL, Williams JBW, Berry JT, Mokdad AH. The PHQ-8 as a measure of current depression in the general population. J Affect Disord 2009;114(1-3):163-173.

108. Spitzer RL, Kroenke K, Williams JBW, Löwe B. A brief measure for assessing generalized anxiety disorder: the GAD-7. Arch Intern Med. 2006;166(10):1092-7

109. Horne R, Weinman J, Hankins M. The beliefs about medicines questionnaire: the development and evaluation of a new method for assessing the cognitive representation of medication. Psychol Health. 1999;14(1):1-24.

Ready to submit your research? Choose BMC and benefit from:

- fast, convenient online submission

- thorough peer review by experienced researchers in your field

- rapid publication on acceptance

- support for research data, including large and complex data types

- gold Open Access which fosters wider collaboration and increased citations

- maximum visibility for your research: over $100 \mathrm{M}$ website views per year

At BMC, research is always in progress.

Learn more biomedcentral.com/submissions 